\title{
IV. On the discovery of four transition points in the spectrum and the primary colour sensations
}

\author{
Frank Allen Ph.D. F.R.S.C.
}

To cite this article: Frank Allen Ph.D. F.R.S.C. (1919) IV. On the discovery of four transition points in the spectrum and the primary colour sensations, Philosophical Magazine Series 6, 38:223, 55-81, DOI: $10.1080 / 14786440708635929$

To link to this article: http://dx.doi.org/10.1080/14786440708635929

曲 Published online: 08 Apr 2009.

Submit your article to this journal $\sqsubset \pi$

Џll Article views: 2

Q View related articles $\square$

Citing articles: 1 View citing articles 5 
If vapour is given off from the drop it will condense to form a primary composite surface, and this being contractile may pull the drop itself out to form a secondary surface. The fact that B.P. "paraffin " and castor oil do not spread at all on clean glass is due to their low vapour pressure, and is no evidence as to the tension of the glass-oil interface.

I confess I should not have expected that a film of fluid of the order of 1 micron in thickness on a solid face would be spontaneously contractile, but the migration of the drops of acetic acid appears to afford conclusive evidence on this point. Any primary. composite surface will contract only if a further thickening of the film lowers the surface tension. A fully formed primary surface, that is to say one in which the film has thickened to the point at which the function $\frac{d \mathrm{~T}}{d x}$ (where ' $\mathrm{l}$ ' is the tension, and $x$ the thickness of the film) changes its sign, would have no tendency to contract; indeed it would resist further contraction. The fact that primary surfaces saturated with fluid actually do contract spontaneously when exposed to air, is due frequently to the thinning of the surface film by evaporation. This is readily demonstrable with pure benzene on water. Substances such as benzene on water and acetic acid on glass behave in fact as though the film on a primary composite surface varied in thickness with variations in the vapour pressure of the fluid of which it is composed. If this be so the film on a composite surface cannot be always and of necessity one molecule thick as some writers suppose.

IV. On the Discovery of Four 'Transition Points in the Spectrum and the Primary Colour Sensations. By Frank A.luen, Ph.D., F.R.S.C., Professor of Physics, University of Manitoba, Winnipeg*.

rJHE researches in colour-vision which I have made from 1 time to time have had for their secondary object the extension of our knowledge of the persistence of vision, and for their primary object the determination in an incontrovertible manner, if possible, of the number of fundamental coloursensations, and the precise waves of light by which they are excited, concerning which there has been and still is much controversy.

In this communication I have gathered togetber some

* Communicated by the Author. 
results previously published, and incorporated with them new investigations which appear absolutely to determine the number of the fundamental colour-sensations. With the method of study which I have used it does not yet seem possible to designate the exact waves of light which excite the primary sensations of colour; but it is possible to determine the limits between which these hues nust lie.

The apparatus used for purposes of measurement was similar to that described in a former paper* ${ }^{*}$, and essentially the same as that devised and used by E. L. Nichols $\dagger$. Light from an acetylene flame passed through i disk with two opposite open sectors of ninety degrees each, whose speed of rotation was electrically recorded upon a cbronograph. The flickering light was dispersed into a spectrum by at suitable spectrometer, and a shutter eyepiece enabled observations to be made as desired upon narrow strips of the spectrum. The speed of the disk was adjusted so that the flickering of the light became just imperceptible and then recorded. The arrangement is shown by the diagram in fig. 1.

Fig. 1.
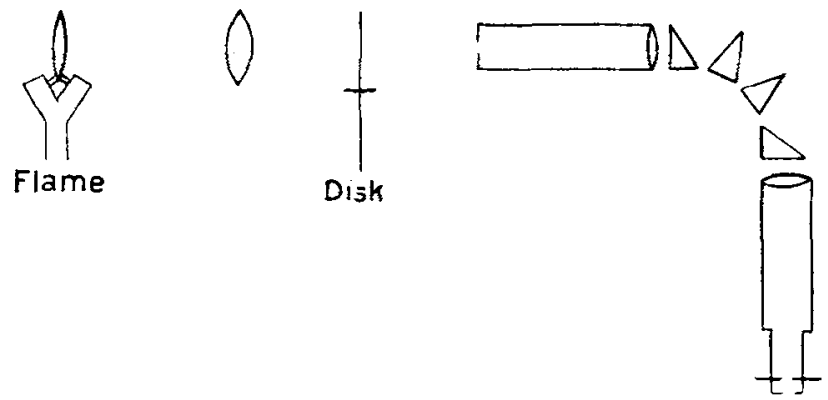

By means of an arc-light and a second spectrometer with two prisms, a brilliant spectrum of considerable dispersion was formed, narrow portions of which were isolated by a shutter eyepiece, and used to fatigue the eye with which observations of the persistence of vision were made. An interval of time of about three minutes was allowed for fatiguing the eye before each measurement of the criticil time of flicker was made. In this way a persistency curve

*Allen, "Effect on the Persistence of Vision of Exposing the Eye to Light of Various Wave-Lengtha," Phys. Rev. xi. 1900.

t "On the Duration of Colour Impressions on the IRetina," A m. Journ. Sci. xxviii. 1884. 
Spectrum and the Primary Colour Sensations.

for the whole spectrum was obtained which can be compared with a normal curve previously determined when the eye was adapted for diffused daylight. At various times these curves have been obtained, and in this paper seventeen of them are compared and discussed.

In two former investigations * curves were described for seven portions of the spectrum, viz.: for red, orange, yellow, green, blue, and violet, the wave-lengths of which were respectively $\lambda \cdot 680 \mu, \lambda \cdot 620 \mu, \lambda \cdot 589 \mu, \lambda \cdot 577 \mu, \lambda \cdot 520 \mu$, $\lambda \cdot 440 \mu$, and $\lambda \cdot 400 \mu$. These curves are all reproduced in this paper.

In a communication to the British Association $\dagger$ at its

Fig. 2.

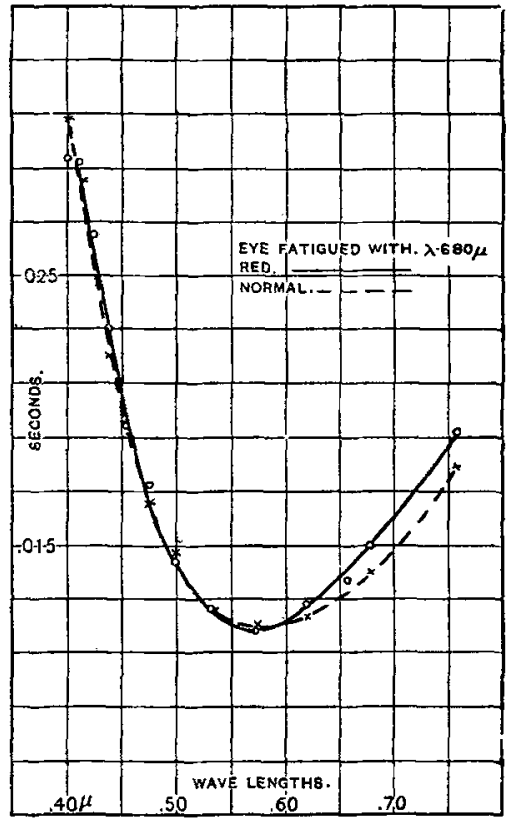

Winnipeg meeting, I pointed out a very curious and remarkable effect occurring when the fatiguing colour was $\lambda \cdot 660 \mu$. It will be noticed from fig. 2 that the persistency

* "Effect on Persistence of Vision, etc.," Phys. Rev. xi. 1900. "Some P'henomena of the Persistence of Vision," Phys. Rev. vol. xxviii. 1909. Also Trans. Roy. Can. 1908.

$\dagger$ Report of B.A.A.S. 1909, p. 410. 
curve obtained when the eye was fatigued with a pure red of wave-length $\lambda \cdot 680 \mu$ has in it a single characteristic elevation which corresponds to the red portion of the spectrum, the rest of the curve coinciding with the normal. It will also be noticed from fig. 8 , that when the fatiguing colour was the wave-length $\lambda .589 \mu$, there were two elevations in the curve, one in the red as before, and the second in the part corresponding to green. It occurred to me that there inust be in the spectrum a point of transition from the type of curve with one elevation to that with two, and that the curve obtained when this transition point was made the fatiguing colour would probably differ in some way from both. Accordingly, search was made for it. The eye was fatigued with the colour $\lambda \cdot 670 \mu$, and the readings in Table I. were obtained.

\section{'TABLE I.}

\begin{tabular}{|c|c|c|c|c|c|}
\hline$\lambda$. & $\begin{array}{c}\text { Normal } \\
\text { Persistence. }\end{array}$ & $\begin{array}{l}\text { Eye fatigued } \\
\text { with } \lambda \cdot 670 \mu \text {. }\end{array}$ & $\lambda$. & $\begin{array}{c}\text { Nornal } \\
\text { Persistence. }\end{array}$ & $\begin{array}{l}\text { Eye fatigued } \\
\text { with } \lambda \cdot 670 \mu \text {. }\end{array}$ \\
\hline $\begin{array}{l}733 \mu \\
695\end{array}$ & $\begin{array}{l}.0340 \mathrm{sec} \\
.0248\end{array}$ & $\begin{array}{l}.0880 \text { sec. } \\
.0266\end{array}$ & $\begin{array}{l}\cdot 530 \mu \\
-500\end{array}$ & $\begin{array}{l}.0171 \text { sec. } \\
.0215\end{array}$ & $\begin{array}{l}.0175 \text { sec. } \\
0224\end{array}$ \\
\hline 663 & $\cdot 0198$ & .0214 & .470 & & .0306 \\
\hline 01 & .0156 & .0155 & $\cdot 460$ & $\cdot 0332$ & $\ldots$ \\
\hline 564 & $\cdot 0157$ & .0155 & $\cdot 430$ & $\cdot 0513$ & $\ldots$ \\
\hline
\end{tabular}

These values are plotted in fig. 3 , and give a curve with one elevation, similar to that for the wave-length $\lambda \cdot 680 \mu$. Similarly, curves were obtained for the wave-lengths $\lambda \cdot 651 \mu$ and $\lambda \cdot 625 \mu$, the data for which are tabulated in Table II. and Table III. respectively.

\section{TABLE II.}

\begin{tabular}{|c|c|c|c|c|c|}
\hline$\lambda$. & $\begin{array}{c}\text { Normal } \\
\text { Persistence. }\end{array}$ & $\begin{array}{r}\text { Eye fatigued } \\
\text { with } \lambda \cdot 651 \mu \text {. }\end{array}$ & $\lambda$. & $\begin{array}{c}\text { Normal } \\
\text { Persistence. }\end{array}$ & $\begin{array}{l}\text { Eye fatigued } \\
\text { with } \lambda \cdot 601 \mu .\end{array}$ \\
\hline $\begin{array}{l}733 \mu \\
695\end{array}$ & $\begin{array}{l}.0318 \mathrm{sec} . \\
.0232\end{array}$ & $\begin{array}{l}.0353 \text { sec. } \\
.0254\end{array}$ & $\begin{array}{l}.530 \mu \\
.500\end{array}$ & 0̈̈89 sec. & $\begin{array}{l}.0177 \text { sec. } \\
.0189\end{array}$ \\
\hline 663 & .0185 & .0197 & .460 & .0310 & ... \\
\hline 601 & .0144 & .0145 & .430 & $\cdot 0458$ & $\ldots$ \\
\hline-564 & .0147 & .0153 & $\ldots$ & $\ldots$ & $\ldots$ \\
\hline
\end{tabular}

Table III.

\begin{tabular}{|c|c|c|c|c|c|}
\hline$\lambda$. & $\begin{array}{c}\text { Normal } \\
\text { Persistence. }\end{array}$ & $\begin{array}{l}\text { Eye fatigned } \\
\text { with } \lambda \cdot 625 \mu \text {. }\end{array}$ & $\lambda$. & $\begin{array}{c}\text { Normal } \\
\text { Persistence. }\end{array}$ & $\begin{array}{l}\text { Eye fatigued } \\
\text { with } \lambda \cdot 625 \mu \text {. }\end{array}$ \\
\hline$-733 \mu$ & $\begin{array}{l}-0318 \text { sec. } \\
.0232\end{array}$ & $\begin{array}{l}.0364 \text { sec. } \\
.0249\end{array}$ & $\begin{array}{l}\cdot 530 \mu \\
.500\end{array}$ & $.0189 \mathrm{sec}$ & $\begin{array}{l}.0170 \text { sec. } \\
.0194\end{array}$ \\
\hline & $\cdot 0185$ & .0190 & $\cdot 460$ & .0310 & $\ldots$ \\
\hline & 0144 & .0144 & $\cdot 430$ & .0458 & $\ldots$ \\
\hline 64 & 0147 & $\cdot 0162$ & $\ldots$ & $\ldots$ & $\ldots$ \\
\hline
\end{tabular}


Fig. 3.

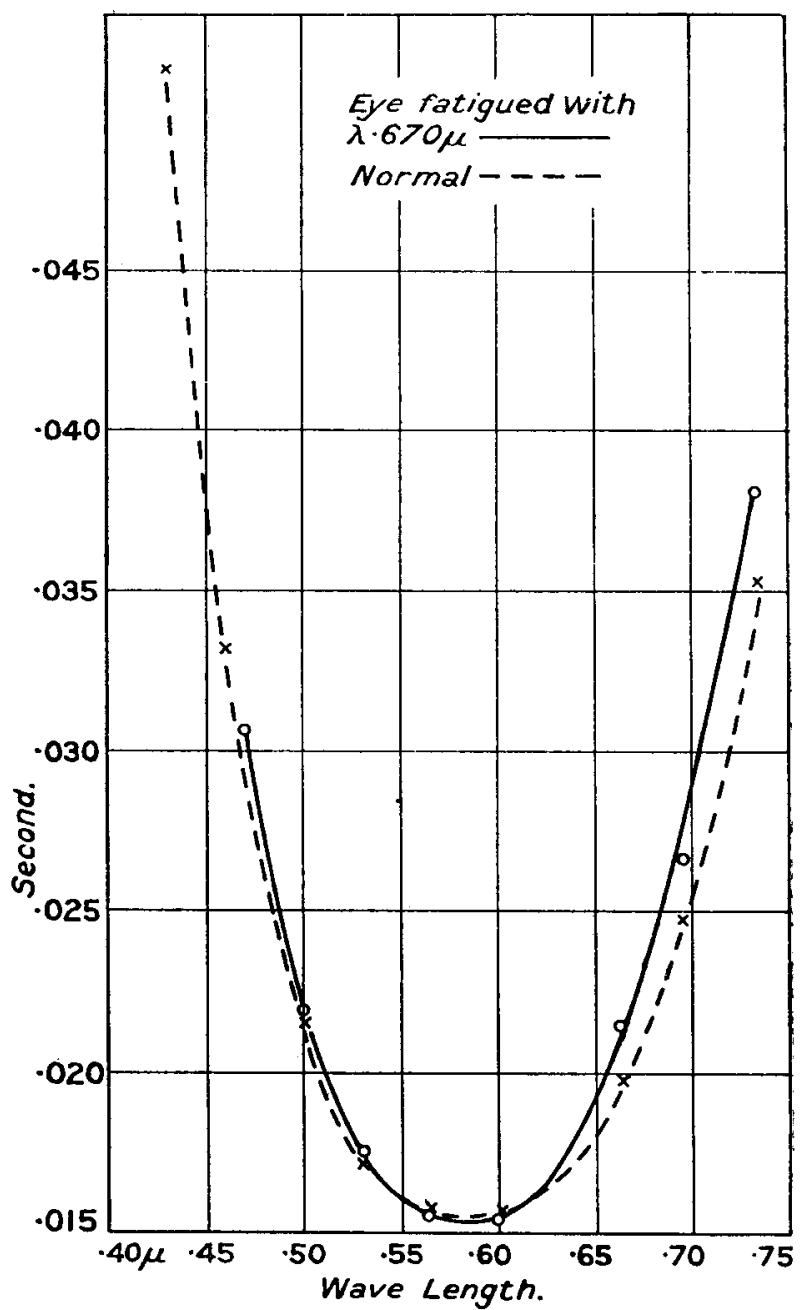

The corresponding curves are shown in fig, 5 and fig. 6 . Both are of the same type, and exhibit two elevations similar to those in the curve for the wave-length $\lambda 589 \mu$ in fig. 8. As these measurements are tedious to make, I yielded to the temptation to determine these curves, and a few others, as will be noticed, only for those parts where experience shows 
the elevations can occur. There can be no doubt that the rest of the curve would coincide with the normal.

Fig. 4.

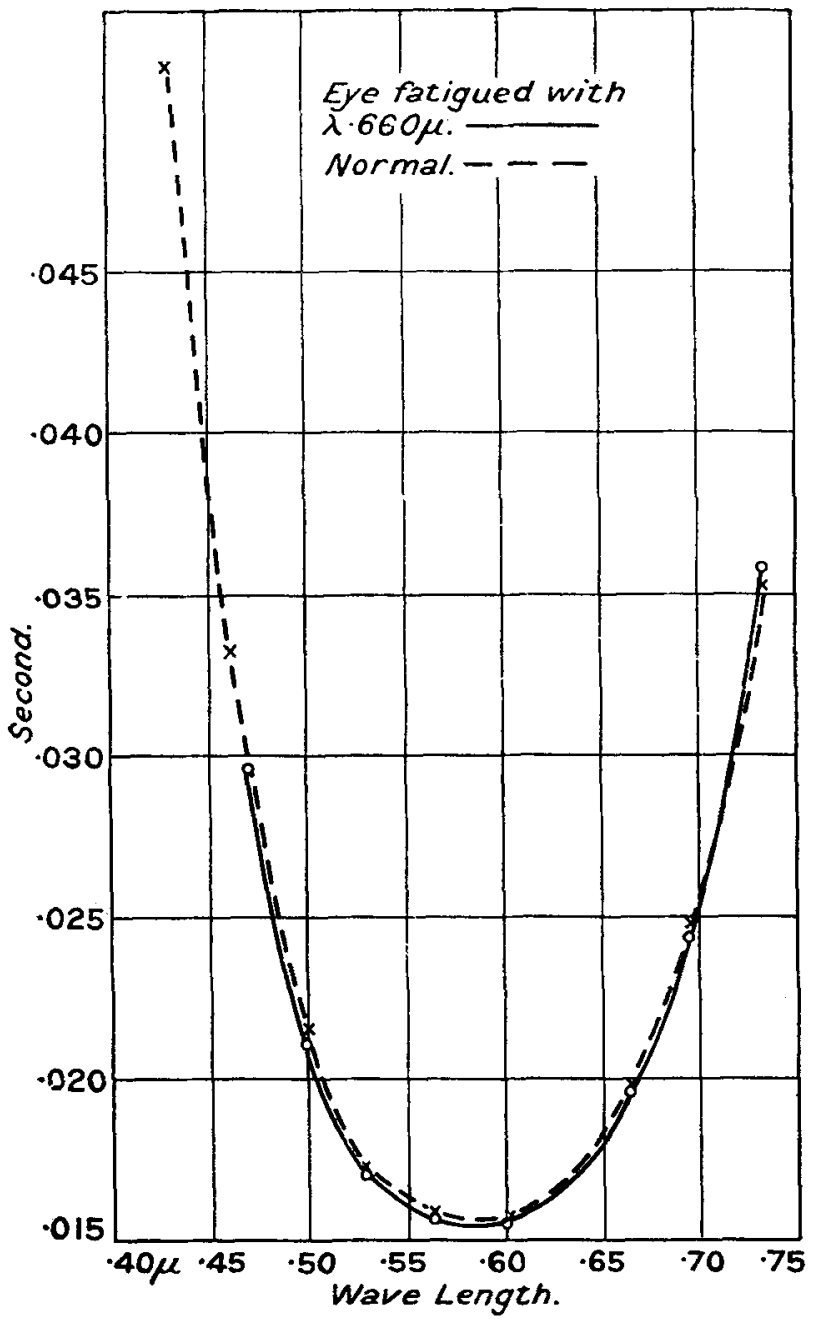

The transition point was thus narrowed down to the wavelength $\lambda \cdot 660 \mu$. The eye, therefore, was fatigued with this colour, and from the data obtained, Table IV., the curve in fig. 4 was plotted. 
Spectrum and the Primary Colour Sensations.

TABLE IV.

Normal Eye fatigued Persistence. with $\lambda: 660 \mu$ $-738 \mu \quad 0353$ sec. $\quad 0358$ sec. $.695 \quad 0248$

$.663 \quad .0198$

$.601 \quad .0156$

$.564 \quad .0157$

.0243

.0196

.0155

$\cdot 0156$

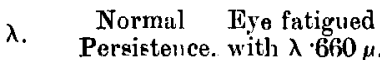

$.530 \mu \quad 0171$ sec. $\cdot 0170$ sec.

$500 \quad .0215 \quad 0211$

$\begin{array}{lll}.470 & \ldots & .0295\end{array}$

$.460 \quad .0332$

$-430 \quad-0513$

Fig. 5.

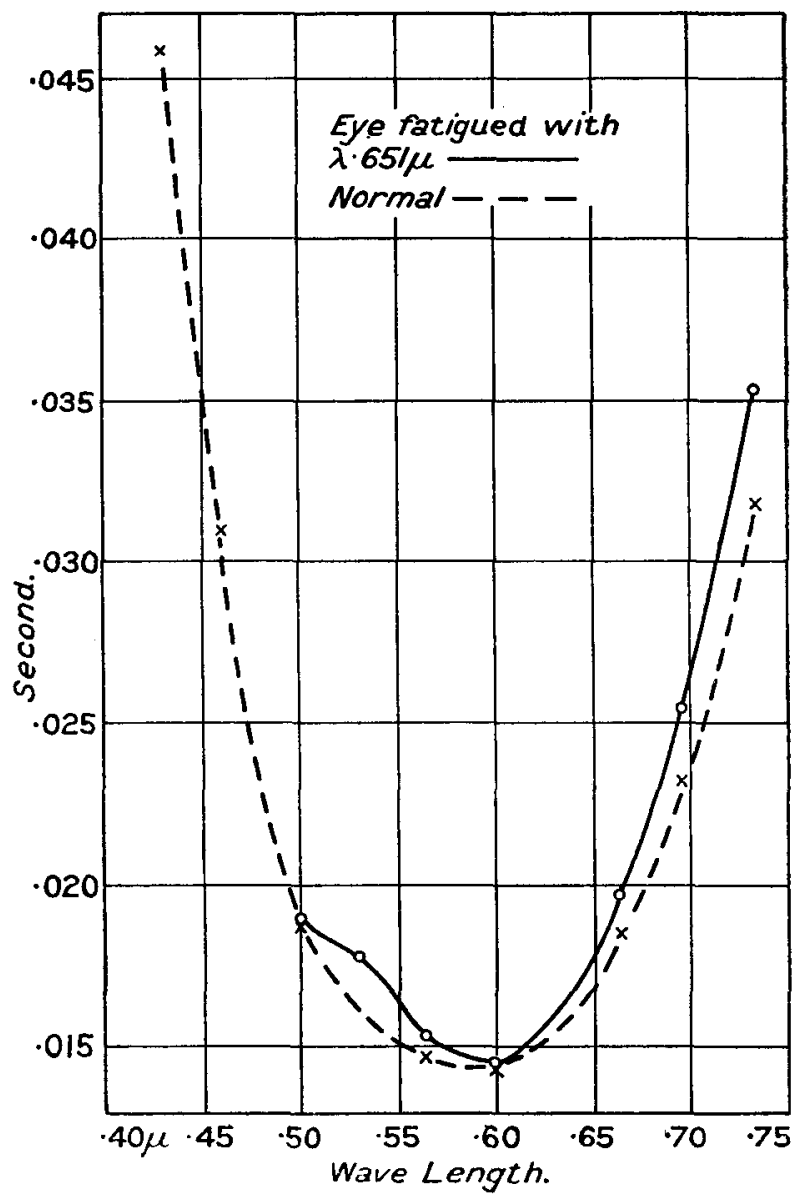

No elevations at all appeared, and the abnormal curve coincided with the normal throughout their length. This surprising result at first was taken to indicate that the eye 
had not been sufficiently fatigued or that the readings were not properly taken. With the greatest care the whole of the readings were repeated on the following day with exactly the same result. The remarkable conclusion follows, that fatiguing the eye with a narrow band of colour whose central wavelength is $\lambda \cdot 660 \mu$, has not the slightest perceptible effect on

Fig. 6.

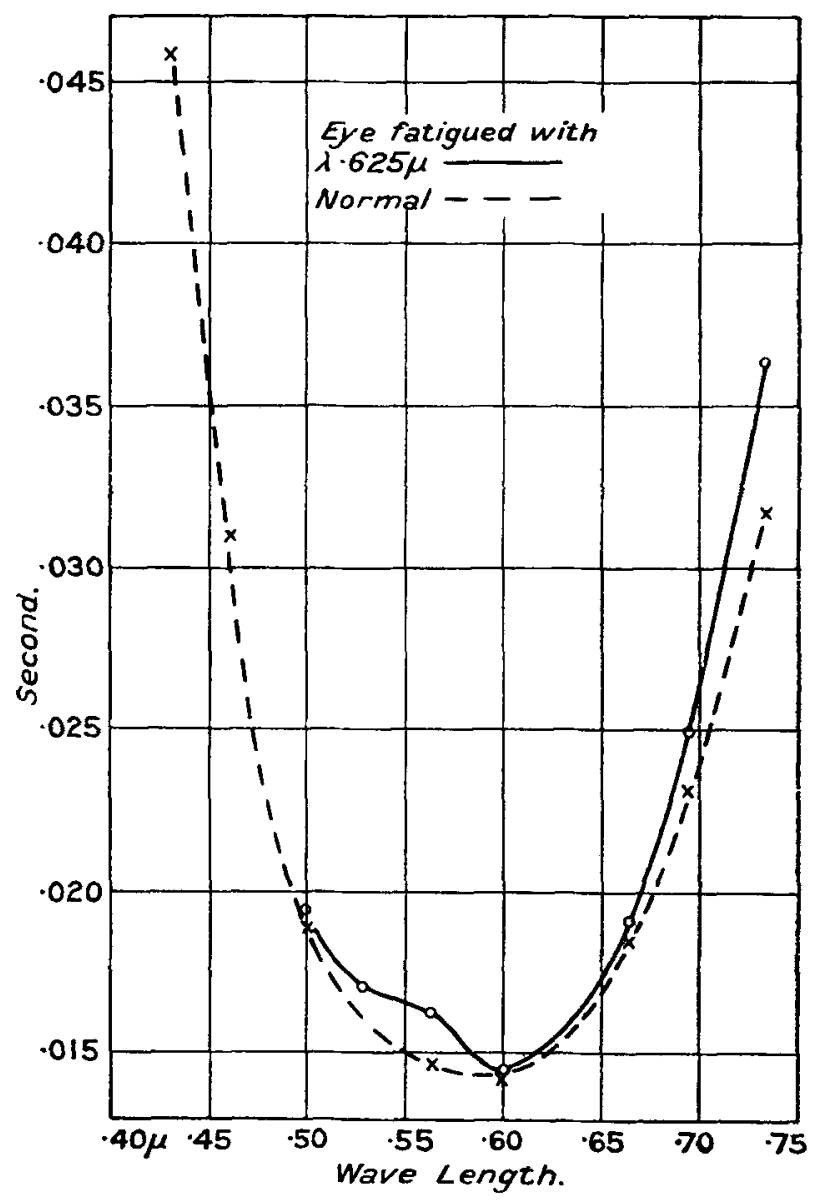

the measurement of the persistence of vision for any part of the spectrum. This wave-length, $\lambda \cdot 660 \mu$, is therefore the transition point between curves of the single red elevation type and those of the double red and green elevation type. 
Spectrum and the Primary Colour Sensations.

Fig. 7 .

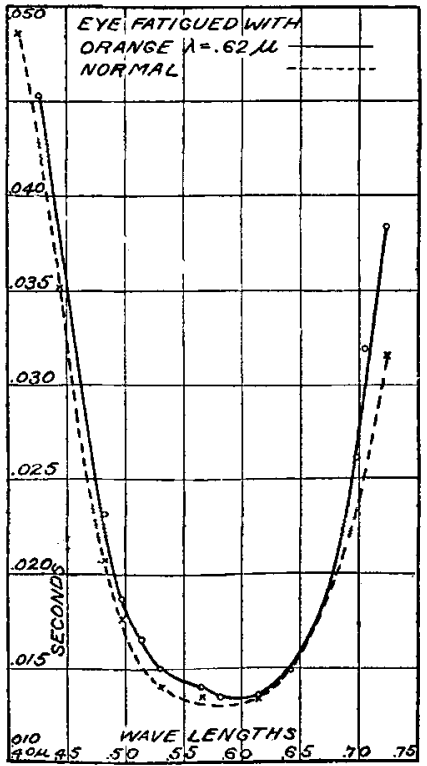

Fig. 8 .

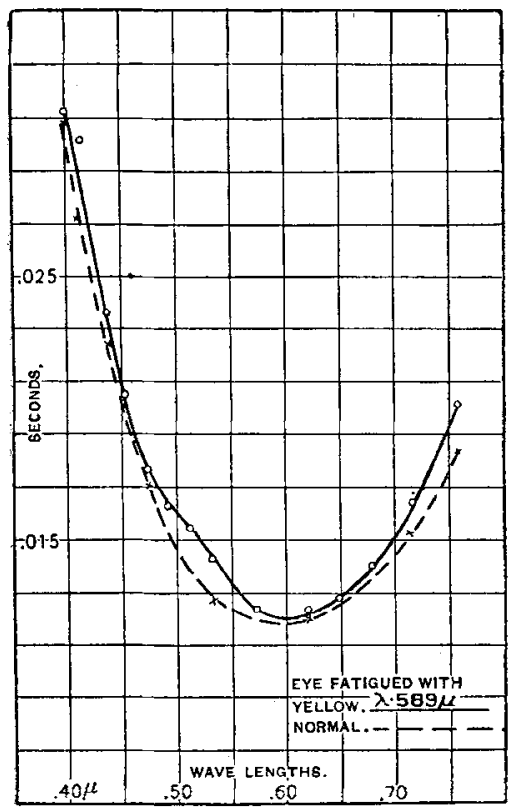


The persistency curve obtained when the eye was fatigued with the wave-length $\lambda \cdot 620 \mu$ is here reproduced in fig. 7 from a previous paper to which reference has already been made. This curve is of the double red and green elevation type, similar to the curves of the two figures immediately preceding.

Fig. 9.

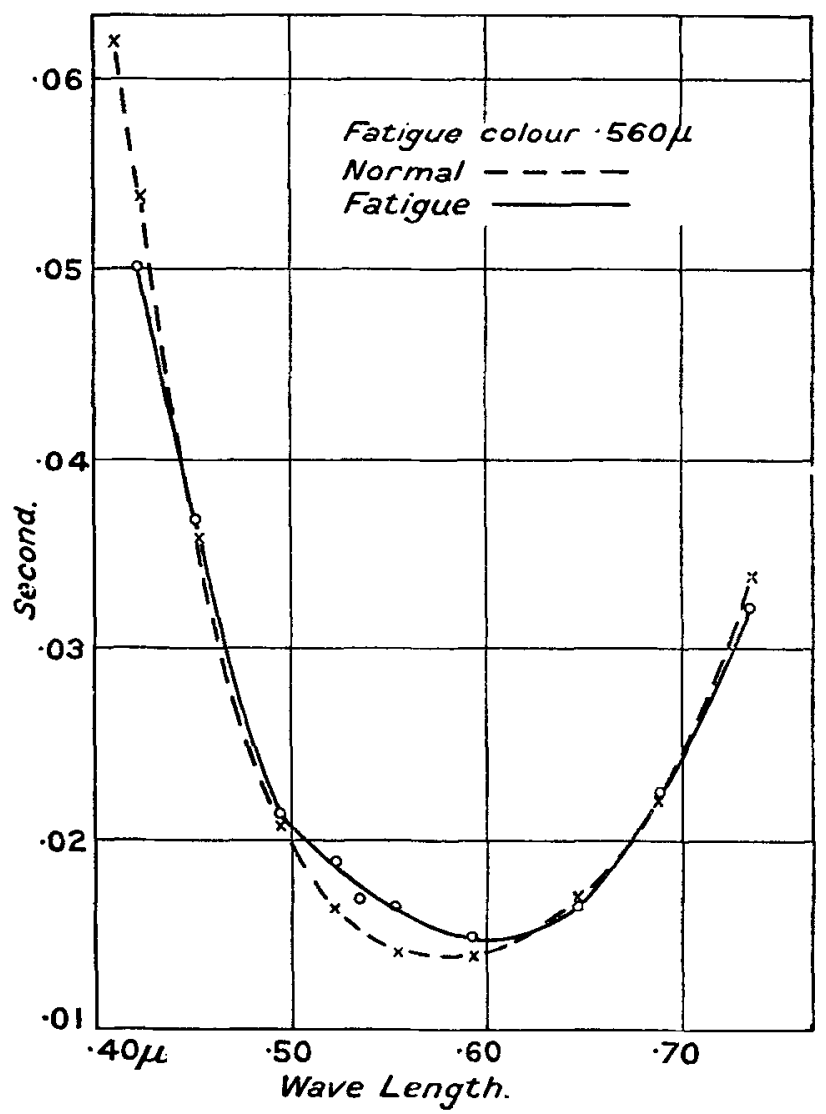

Further consideration led to the conclusion that a second transition point ought to exist between curves of the double red and green elevation type and those of the single green elevation type. Since the curve for the wave-length $\lambda \cdot 520 \mu$, fig. 13, was known from a previous investigation, persistency curves were successively determined with the fatiguing colours $\lambda \cdot 560 \mu$ and $\lambda \cdot 540 \mu$. The data for these are given 
Spectrum and the Primary Colour Sensations.

in Table V. and Table VI., and are plotted in fig. 9 and fig. 10 respectively. Both curves, it will be noticed, are characterized by a single elevation in the green.

Fig. 10.

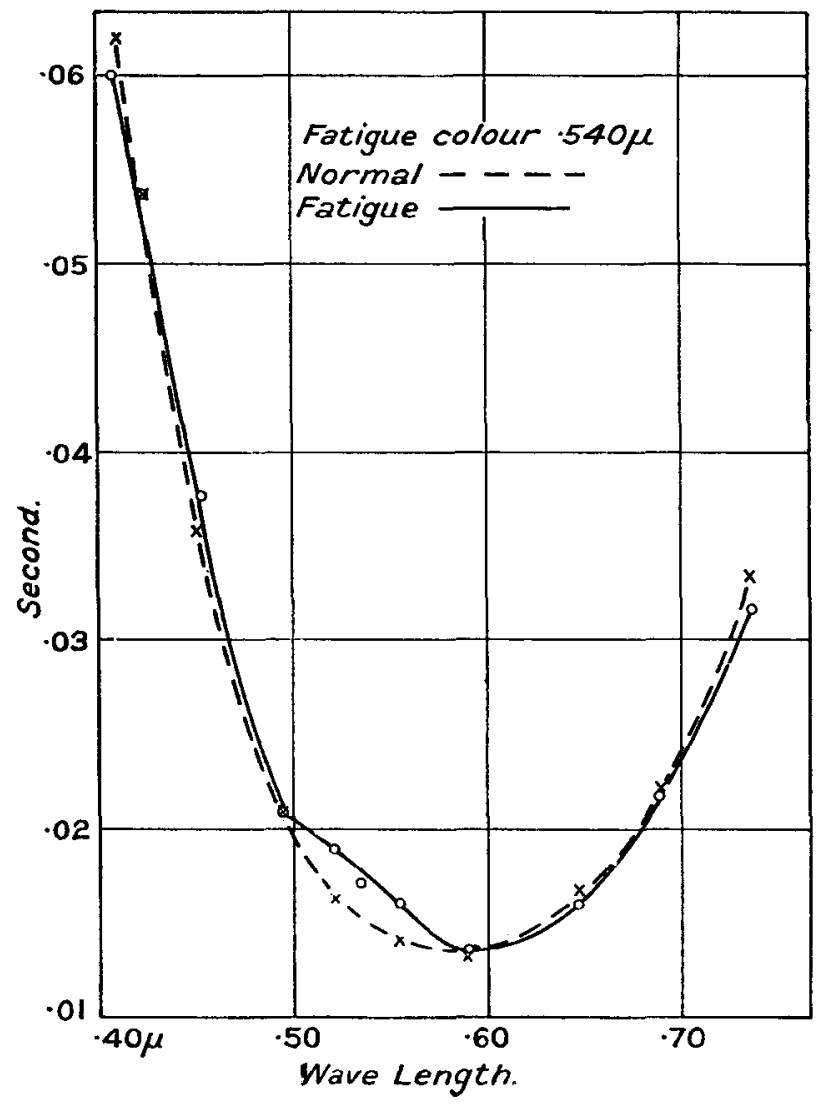

TABLE V.

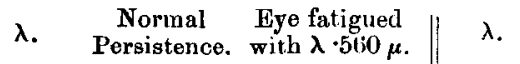
$.735 \mu \quad .0337$ sec. $\quad .0323$ sec. $.690 \quad .0221$

$.647 \quad 0167$

$.593 \quad-0137$

.553

535
.0141

...
0224

.0164

.0144

$\cdot 0164$

.0169 $.522 \mu$ .495 .453 .423 .410
Normal Eye fatigued Persistence, with $\lambda \cdot 560 \mu$. .0164 sec. .0189 sec. .0209 - 1360 .0538 .0620 ...

Phil. Mag. S. 6. Vol. 38. No. 223. July 1919. 
66 Prot. F. Allen on Four Transition Points in the

\section{TABLe VI.}

$\lambda$. Normal Eye futigued Persistence. with $\lambda \cdot 540 \mu$.

$.735 \mu . \quad 0337$ sec. $\quad .0318$ sec.

$.690 \quad .0221$

$.647 \quad 0167$

.593

.553

.535
.0318
.0218

.0161

.0138

0161

0171
Nomal Eye fatigued

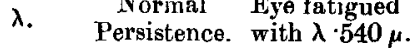
$.522 \mu \quad 0164$ sec. $0190 \mathrm{sec}$.

$.495 \quad .0209 \quad .0209$

$.453 \quad .0360 \quad .0378$

$.423 \quad .0538 \quad .0538$

$.410 \quad .0620 \quad .0602$

Since the persistency curve for the wave-length $\lambda \cdot 577 \mu$, fig. 11, had previously been determined to be of the double

Fig. 11.

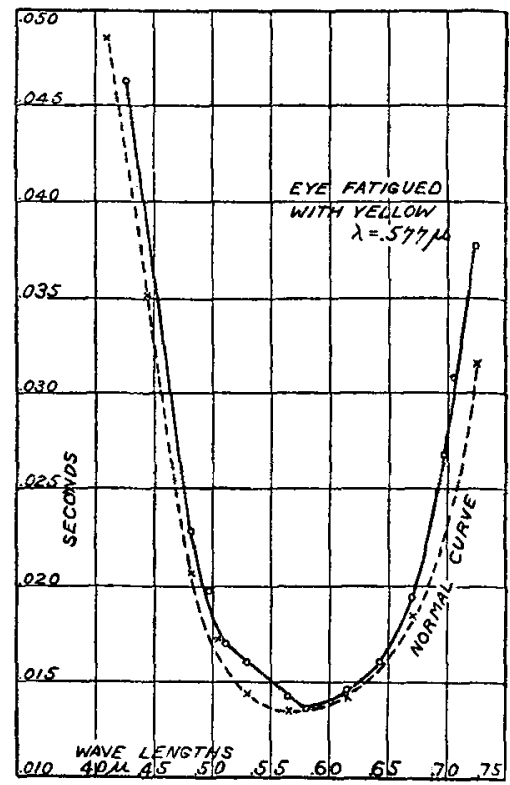

red and green elevation type, it was evident that the transition point must be near $\lambda \cdot 570 \mu$. This hue was then used as the

\section{TABLE VII.}

$\lambda$ Normal Eye fatigued Persistence. with $\lambda \cdot 570 \mu$. $\begin{array}{lll}.735 \mu & .0337 \text { sec. } & .0320 \text { sec. } \\ .690 & .0221 & .0224\end{array}$ $\cdot 690 \quad 0221 \quad .0224$ $.647 \quad 0167 \quad 0168$

$\begin{array}{rll}.593 & \cdot 0137 & 0137\end{array}$

$.553 \quad .0141 \quad .0146$ $\lambda$ Normal Eye fatigued Persistence. with $\lambda \cdot 570 \mu$. $.522 \mu \quad 0164$ sec. 0163 sec. $.495 \mu \quad .0209 \quad .0205$ $\begin{array}{lll}-453 & .0360 & .0365\end{array}$ $.423 \quad 05 \overline{3} \quad 0554$ 
fatiguing colour, and the results given in Table VII. obtained from which the curve in fig. 12 is plotted.

This curve, like that for the first transition point, has no elevations, but coincides at all points with the normal.

Fig. 12.

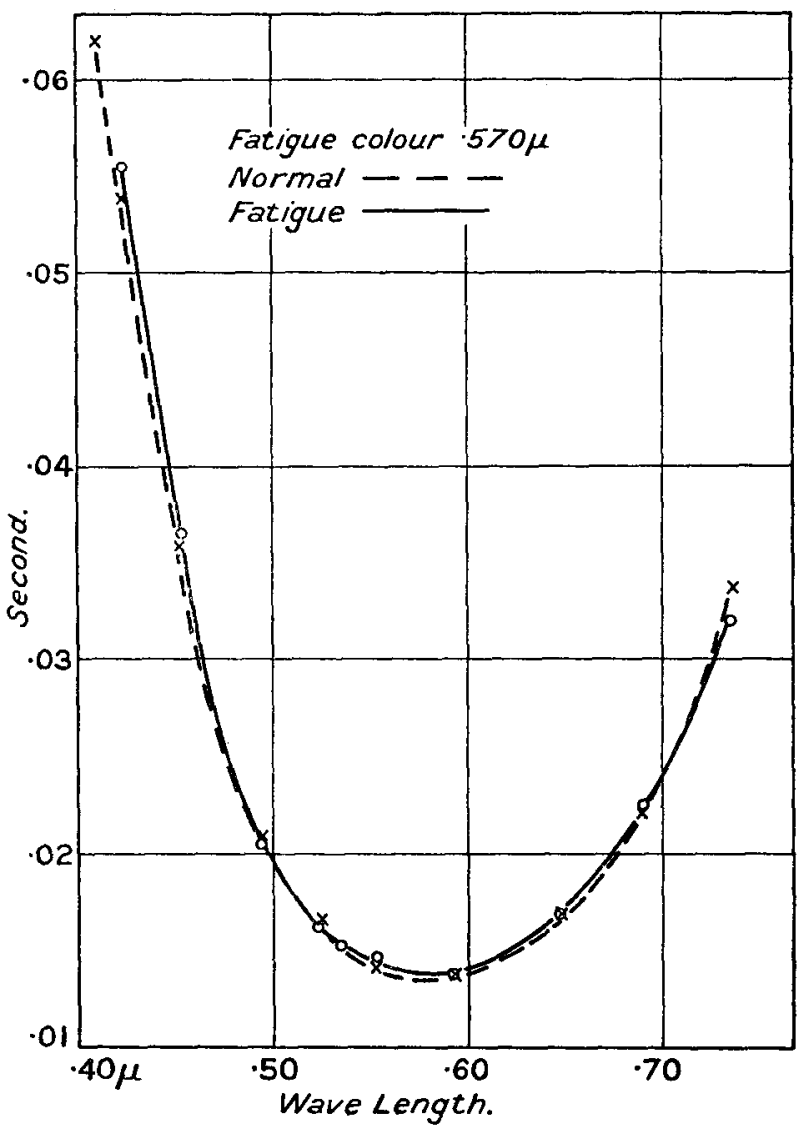

It was now certain that two more transition points existed, one between the single green elevation type of curve, such as that for the wave-length $\lambda \cdot 520 \mu$, fig. 13, and the double green and violet elevation type, like that for the wave-length $\lambda \cdot 440 \mu$, fig. 16 ; and the other marking the transition from 
this latter type of curve to the single violet elevation typo exhibited by that obtained for the wave-length $\lambda \cdot 400 \mu$, fig. 17, which was known from previous work*.

Fig. 13.

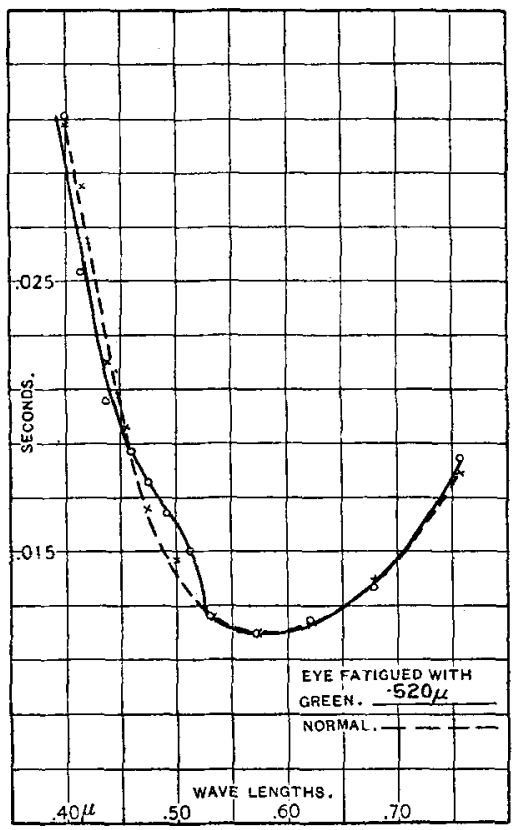

In the process of narrowing down the third transition

* Note. - The readings obtained when the eye was fatigued with the wave-lengths $\lambda \cdot 440 \mu$ and $\lambda \cdot 400 \mu$ are given in the paper already referred to, viz.: "Effect on Persistence of Vision, ets:", Phys. Rev. vol. xi. By some oversight the corresponding normal persistency readings were omitted from that paper, and they are now given here:

\begin{tabular}{|cc||cc||lc}
$\lambda$. & $\begin{array}{c}\text { Normal } \\
\text { Porsistence. }\end{array}$ & $\lambda$. & $\begin{array}{c}\text { Normal } \\
\text { Persistence. }\end{array}$ & $\lambda$. & $\begin{array}{c}\text { Normal } \\
\text { Persistence. }\end{array}$ \\
$758 \mu$ & .0182 sec. & $.622 \mu$ & .0113 sec. & $-428 \mu$ & .0203 sec. \\
7.75 & -0156 & .573 & .0105 & -409 & .0249 \\
.680 & -0134 & .507 & .0120 & -400 & .0277 \\
.647 & .0121 & -465 & .0154 & $\ldots$ & $\ldots$
\end{tabular}


region, the wave-lengths $\lambda \cdot 480 \mu$ and $\lambda \cdot 460 \mu$ were successively used as fatiguing colours, for which the results in Table VIII. and Table IX. were obtained.

\section{TABLE VIII.}

\begin{tabular}{|c|c|c|c|c|c|}
\hline$\lambda$. & $\begin{array}{c}\text { Normal } \\
\text { Persistence. }\end{array}$ & $\begin{array}{l}\text { Eye fatigued } \\
\text { with } \lambda \cdot 480 \mu \text {. }\end{array}$ & $\lambda$. & $\begin{array}{c}\text { Normal } \\
\text { Persistence. }\end{array}$ & $\begin{array}{l}\text { Eye fatigued } \\
\text { with } \lambda \cdot 480 \mu\end{array}$ \\
\hline $35 \mu$ & $\begin{array}{l}\cdot 0230 \mathrm{sec} . \\
\cdot 0171\end{array}$ & $\cdot 023+$ sec. & $\begin{array}{l}.522 \mu \\
.495\end{array}$ & $.017 \mathbf{~ s e c}$ & $\begin{array}{l}.0150 \mathrm{sec} \\
.0168\end{array}$ \\
\hline & .01 & 0147 & $\cdot 453$ & & \\
\hline & 0130 & .01 & 423 & .08 & .03 \\
\hline & & & $\cdot 410$ & & \\
\hline & .0138 & .0141 & .400 & $\cdot 0432$ & $\cdot 0423$ \\
\hline
\end{tabular}

Table IX.

\begin{tabular}{|c|c|c|c|c|c|}
\hline$\lambda$. & $\begin{array}{c}\text { Normal } \\
\text { Persistence. }\end{array}$ & $\begin{array}{c}\text { Eye fatigued } \\
\text { with } \lambda \cdot 460 \mu \text {. }\end{array}$ & $\lambda$. & $\begin{array}{l}\text { Normal } \\
\text { Persistence. }\end{array}$ & $\begin{array}{l}\text { Eye fatigued } \\
\text { with } \lambda \cdot 460 \mu\end{array}$ \\
\hline$-735 \mu$ & $.0230 \mathrm{sec}$ & & $-4 \% \mu$ & $\cdot 0171 \mathrm{sec}$ & 0176 sec. \\
\hline .690 & .0171 & $\ldots$ & $\cdot 453$ & .0246 & .0249 \\
\hline .647 & .0147 & & .423 & .0312 & .0311 \\
\hline .593 & .0130 & $0124 \mathrm{sec}$. & $\cdot 417$ & & $\cdot 0341$ \\
\hline .553 & & .0132 & .41 & .0368 & .0378 \\
\hline .535 & 0138 & $\cdot 0137$ & .405 & & $\cdot 0415$ \\
\hline .522 & $\ldots$ & .0150 & $\cdot 400$ & $\cdot 0432$ & .0426 \\
\hline
\end{tabular}

These curves are exhibited in fig. 14 and fig. 15 respectively. They show no elevations at all, but are coincident with the normal curves. The conclusion appears to be that this trausition region is broader than those previously described, probably because the dispersion of the blue in the prismatic spectrum is greater than that of the red. The wave-lengths $\lambda \cdot 480 \mu$ and $\lambda \cdot 460 \mu$ may be regarded, therefore, as marking the edges of the transition band, the centre being the wave-length $\lambda \cdot 470 \mu$. For this colour no persistency curve was considered necessary. The curve with the wave-length $\lambda \cdot 480 \mu$, fig. 14 , appears to retain a slight vestige of the green elevation which I have indicated by altering the curve at " $b$."

'The fourth and last transition point obviously must lie between the wave-lengths $\lambda \cdot 440 \mu$ and $\lambda \cdot 400 \mu$, since the curve for the former, fig. 16, has two elevations in the green and the violet regions, and that for the latter, fig. 17, only one in the violet. The colour $\lambda \cdot 420 \mu$ was selected for the first trial. This proved to be the desired point, and no other 
70 Prof. F. Allen on Four Transition Points in thes.

Fig. 14.

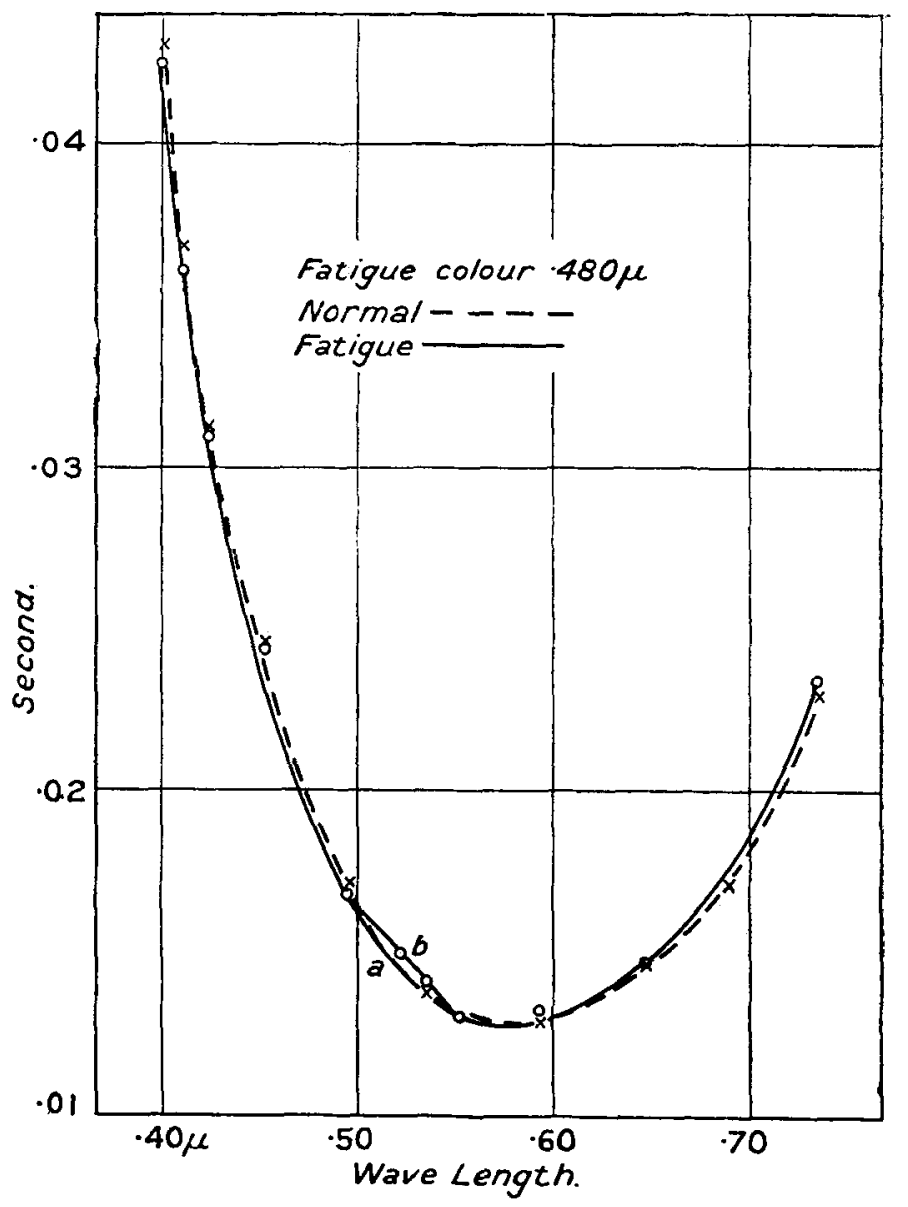

TaBle X.

$\lambda$. Normal Eye fatigued $\quad \lambda$ Normal Eye fatigued $\lambda$. Persistence. with $\lambda \cdot 420 \mu$. $\lambda$. Persistence. with $\lambda \cdot 420 \mu$.

\begin{tabular}{lll||lll}
$.705 \mu$ & .0262 sec. & 0262 sec. & $-465 \mu$ & .0275 sec. & $\ldots$ \\
.665 & .0169 & .0175 & -448 & .0336 & .0339 sec. \\
.626 & .0144 & $\ldots 3$ & -430 & 0392 & .0385 \\
.577 & .0143 & .0145 & -424 & $\ldots$ & .0415 \\
.540 & .0156 & .0153 & -417 & .0450 & .0446 \\
.512 & .0183 & .0179 & -410 & $\ldots$ & .0487 \\
.488 & .0219 & .0215 & -405 & 0530 & .0530
\end{tabular}


Spectrum and the Primary Colour Sensations.

colours on either side were tried. The readings are shown in Table X. and plotted in fig. 18. This curve is without any indication of elevations, and coincides throughout its. course with the normal.

Fig. 15.

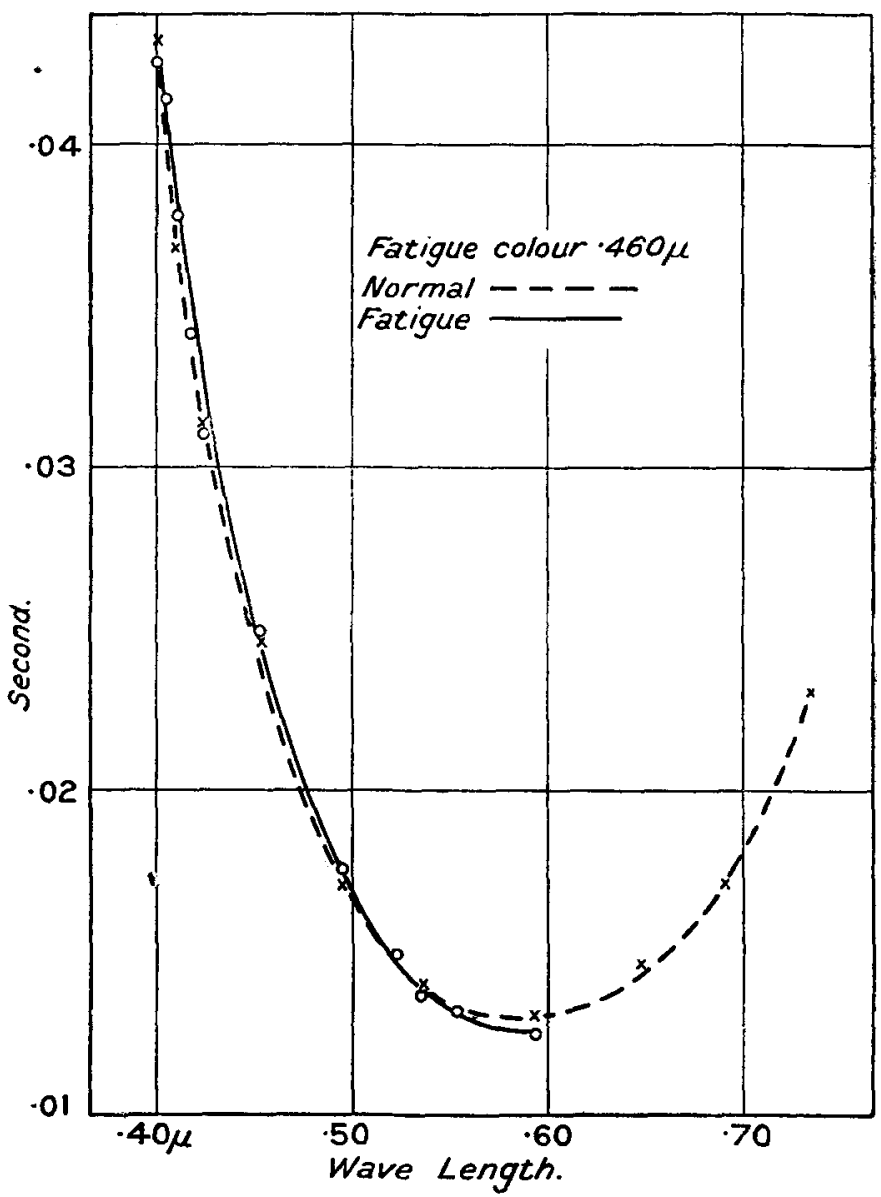

In order to exhibit the seventeen curves described in the preceding pages comprebensively in a simple figure (fig. 19), they have all been replotted so as to make the normal curve a straight line by reducing its scale in all 
parts to the arbitrary value of 100 , and the values of the abnormal curves in the same ratio. Slight departures of the abnormal from the normal curves have been ignored,

Fig. 16.

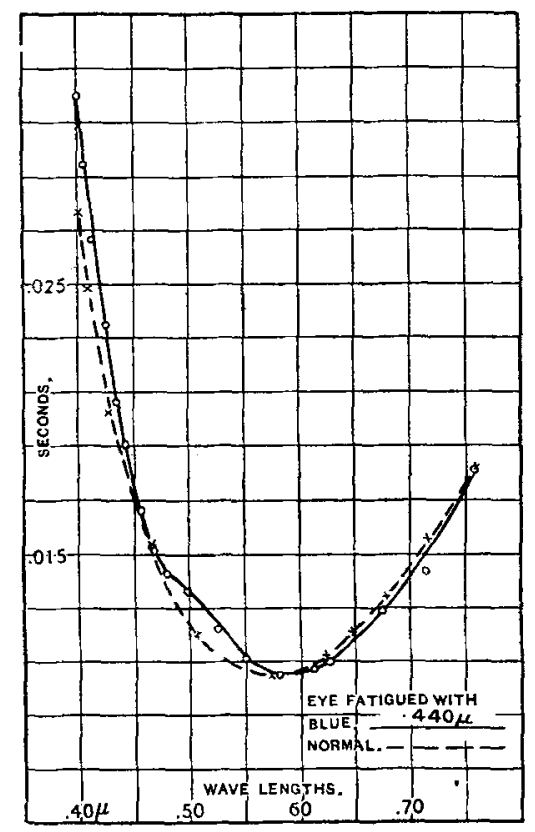

long experience having shown that they are without significance, and to be attributed rather to the inevitable errors of observation.

The elevations of the curves, both single and double, can be readily recognized and compared, and their limiting wavelengths noted. As they are arranged in ascending order of wave-lengths, with the shortest, violet, at the bottom, the curves for the four transition points fall into their proper places, and show their relation to the curves of the other types. Each band of colour used for fatiguing the eye is indicated by a short vertical line just above the normal curve.

Finally, the seventeen curves have been consolidated into a single composite curve by taking the mean values for all the elevations of all the curves. These values are shown in 
Spectrum and the Primary Colour Sensations.

Table XI., and are plotted on an enlarged scale in fig. 20. The four transition points are indicated by short vertical

Fig. 17.

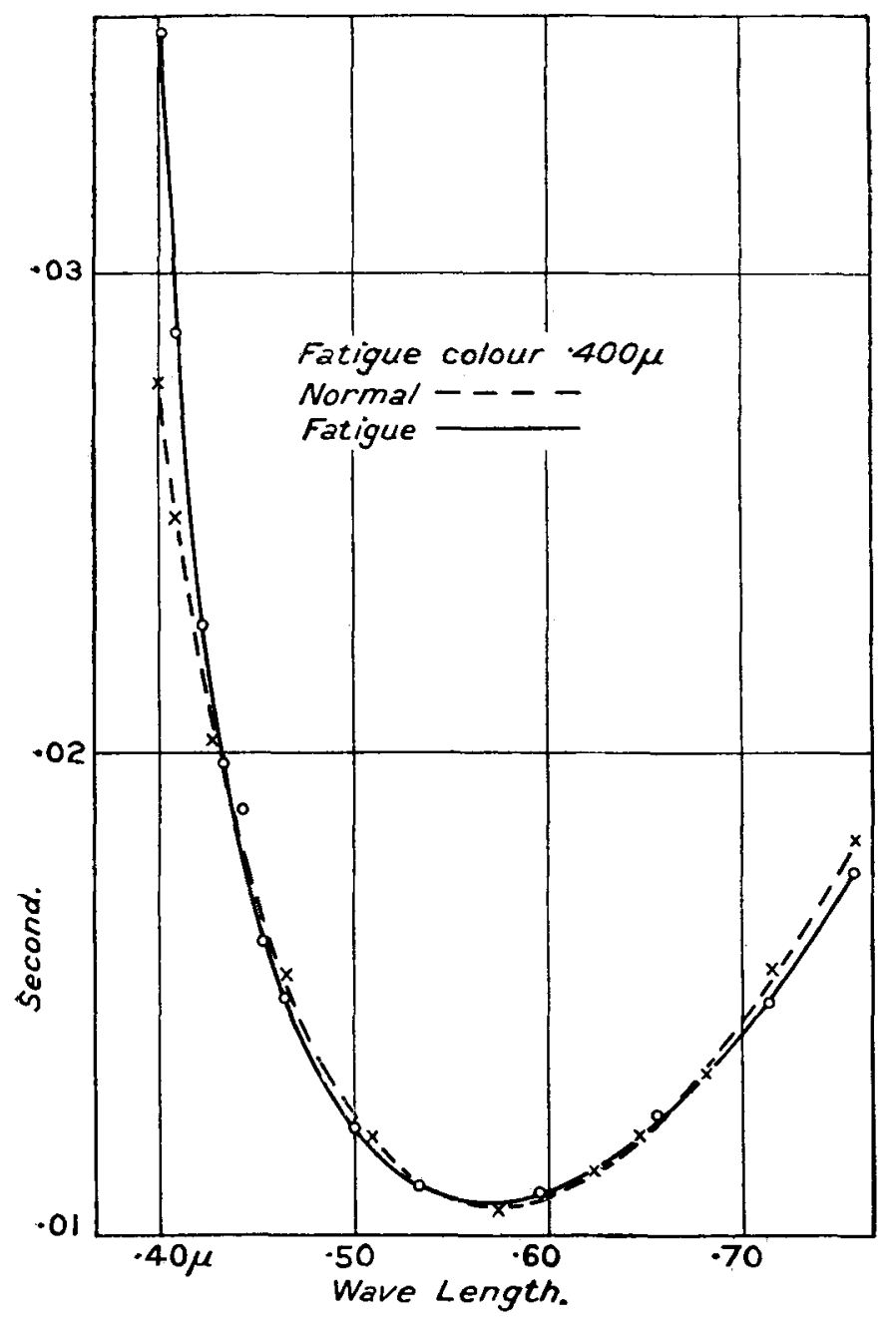

lines as before, and are arranged in pairs quite symmetrically situated in relation to the two minima of the curve. 
74 Prof. F. Allen on Four Transition Points in the

Fig. 18.

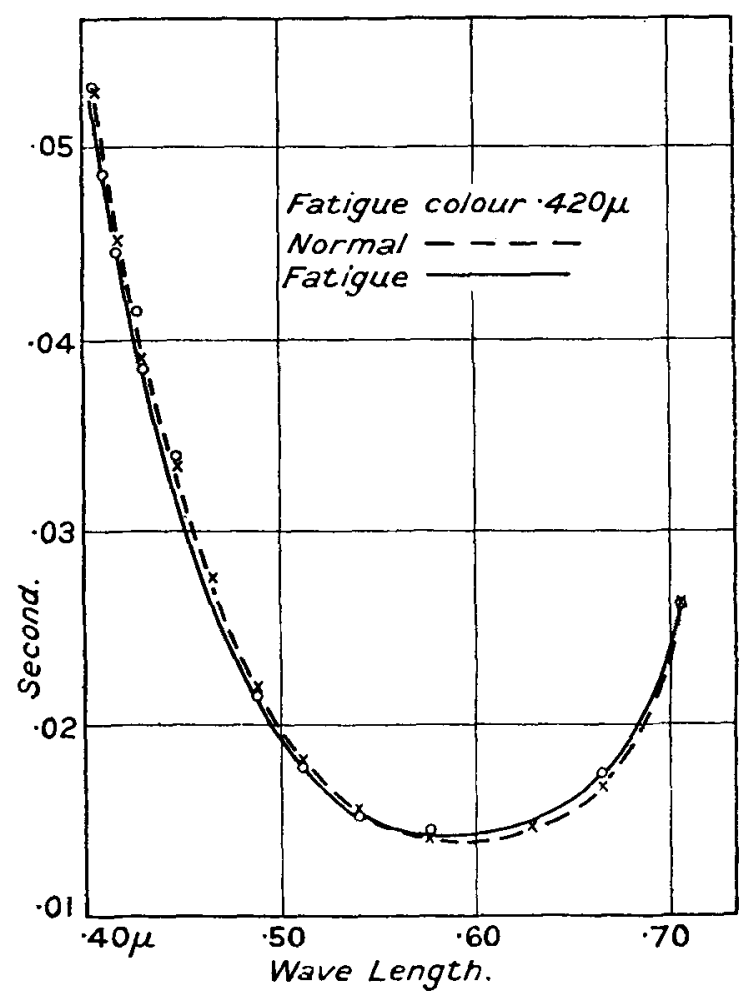

The three elevations of this curve are strongly indicative of a trichromatic basis for the perception of colour.

\section{Table Xr.}

\begin{tabular}{|c|c|c|c|c|c|c|c|}
\hline$\lambda$. & $\begin{array}{c}\text { Mean } \\
\text { Ratio. }\end{array}$ & $\lambda$. & $\begin{array}{l}\text { Mean } \\
\text { Ratio. }\end{array}$ & & $\begin{array}{l}\text { Mean } \\
\text { Ratio. }\end{array}$ & $\lambda$. & $\begin{array}{l}\text { Mean } \\
\text { Ratio. }\end{array}$ \\
\hline $400 \mu$ & 122 & $\cdot 480 \mu$ & 1047 & ${ }_{5}^{566 \mu} \mu$ & & $-663 \mu$ & 106 \\
\hline & 114 & $\cdot 490$ & 10 & 600 & 1007 & 677 & 108 \\
\hline 42 & 11 & $\cdot 500$ & 107.5 & $\cdot 620$ & 100 & 695 & 110 \\
\hline & 10 & -51 & $109 \cdot 5$ & 63 & & .71 & \\
\hline 455 & 100 & $\cdot 523$ & 11 & $\cdot 640$ & & 73 & 112 \\
\hline 470 & $102 \cdot 7$ & 550 & 109 & 650 & 104 & 758 & 110 \\
\hline
\end{tabular}

The general results in this paper may be represented diagrammatically as in fig. 21. In this diagram the indicated wave-lengths mark the transition points and divide the spectrum into five parts. It is evident that the fundamental 
Fig. 19.

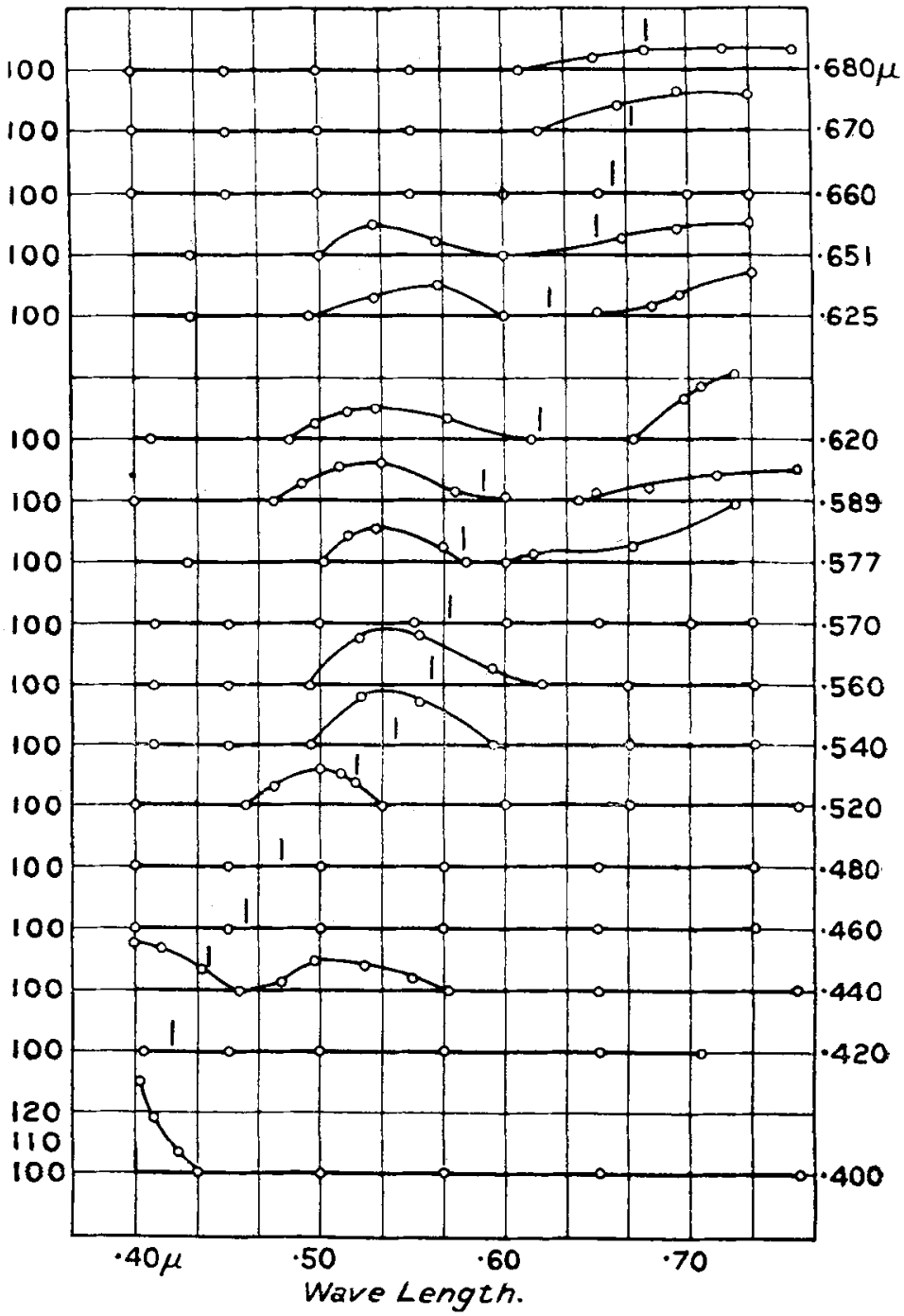

red sensation corresponds to some hue between the beginning of the red and the point of transition at $\lambda \cdot 660 \mu$. Similarly, the fundamental green sensation is excited by some portion of the spectrum lying between the second and third transition 
points at the wave-lengths $\lambda \cdot 570 \mu$ and $\lambda \cdot 470 \mu$. Finally, the third fundamental sensation, which must be violet and not blue as many colour-theorists allege, lies between the fourth point of transition at $\lambda \cdot 420 \mu$ and the end of the violet. It is to be regretted that this method of investigntion does not yet enable us to discover the exact fundamental hues. It is possible that the method of fatiguing the eye with carefully selected pairs of colours at one time, such as I have used in another investigation*, or even with three colours

Fig. 20.

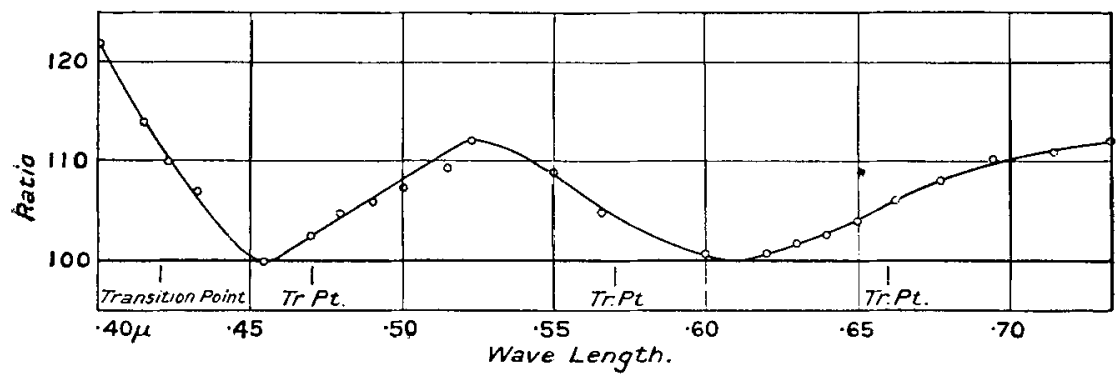

Fig. 21.

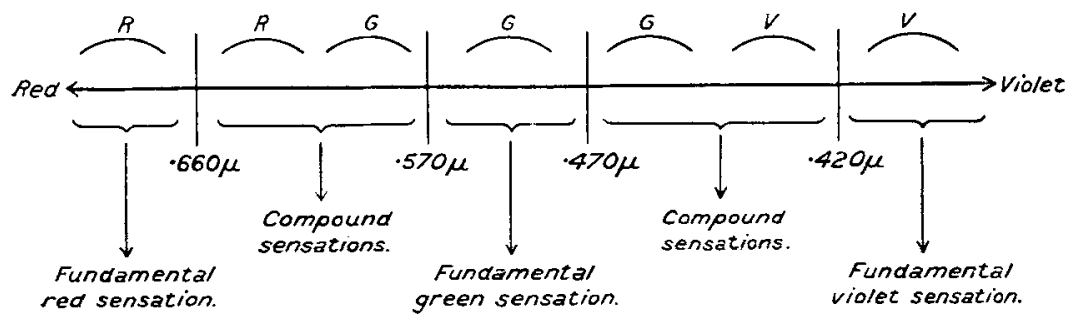

simultaneously, will bring the desired precision. Undoubtedly such investigations will elicit much new information on the complex and apparently inexhaustible phenomena of colour-vision.

One of the most persistent problems in colour-vision is the proper disposition of yellow. In purity of appearance it seems to have quite as much claim as red and green to bs regarded as primary in its nature. Indeed, the psychologists quite universally recognize fully the primary quality of the sensation of yellow. But the five persistency curves obtained between the wave-lengths $\lambda \cdot 660 \mu$ and $\lambda \cdot 570 \mu$ are identical

* "Some Phenomena of the Persistence of Vision," Phys. Rev. vol, xxviii. (1909). 
in their nature, and therefore in the conclusions to be drawn from them. This region includes orange as well as yellow. No one doubts that orange is a compound sensation; and since, according to the curves, the purest yellow has precisely the same effect on the eye, it must likewise be a compound sensation. The same reasoning applies to blue, which also must be compound in its nature.

The existence of three sharply-defined regions of the spectrum exhibiting curves of the single elevation type, corresponding to red, green, and violet, proves conclusively the existence in the eye of three primary sensations corresponding to these colours. 'The concurrent evidence that yellow and blue are compound sensations completes the proot.

The evidence presented in this paper for the existence of but three fundamental colour-sensations is entirely the result of experiments made upon the normal retina. This may be supplemented and greatly strengthened by comparison with persistency curves obtained by persons who are colour-blind. In a former investigation * I studied by this method twentyseven cases of abnormal colour-rision; and in fig. 22 , from that paper, there are shown six out of the seven representative classes into which cases of colour-blindness naturally fall. The persistency curves are drawn after the manner of those in fig. 19; the straight borizontal line at $O$ is my own normal curve, and the other compared with it is that obtained by the colour-blind person. These curves were determined when the eyes were not fatigued, but were rested in ordinary daylight.

In fig. 22 Class $I$. is a curve with one elevation in the red, indicating red-blindness; Class II. shows one elevation in the green, the characteristic of green-blindness; Class III. shows two elevations, one in the red and the other in the green, indicating a type of blindness involving those two colours; Class IV. is a modification of the same type as Class IIl.; Class V. has two elevations, one in the red and the other in the violet, another type of colour-blindness involving two colours; Class VI. has two elevations, one in the green and the other in the violet, still another type, being the third possible variety of colour-blindness involving two colours; Class VII. is that of a totally colour-blind person, and show's the elevation of the whole curve. These persistency curves for eyes that are naturally colour-blind show exactly the same elevations that are obtained for the normal eye when fatigued

* "Persistence of Vision in Colour-blind Subjects," Phys. Rev. vol. xv. (1902). 
by various spectral colours. These curves for colour-blindness, therefore, constitute strong additional evidence for the existence of three primary colous-sensations-red, green, and violet.

Fig. 22.

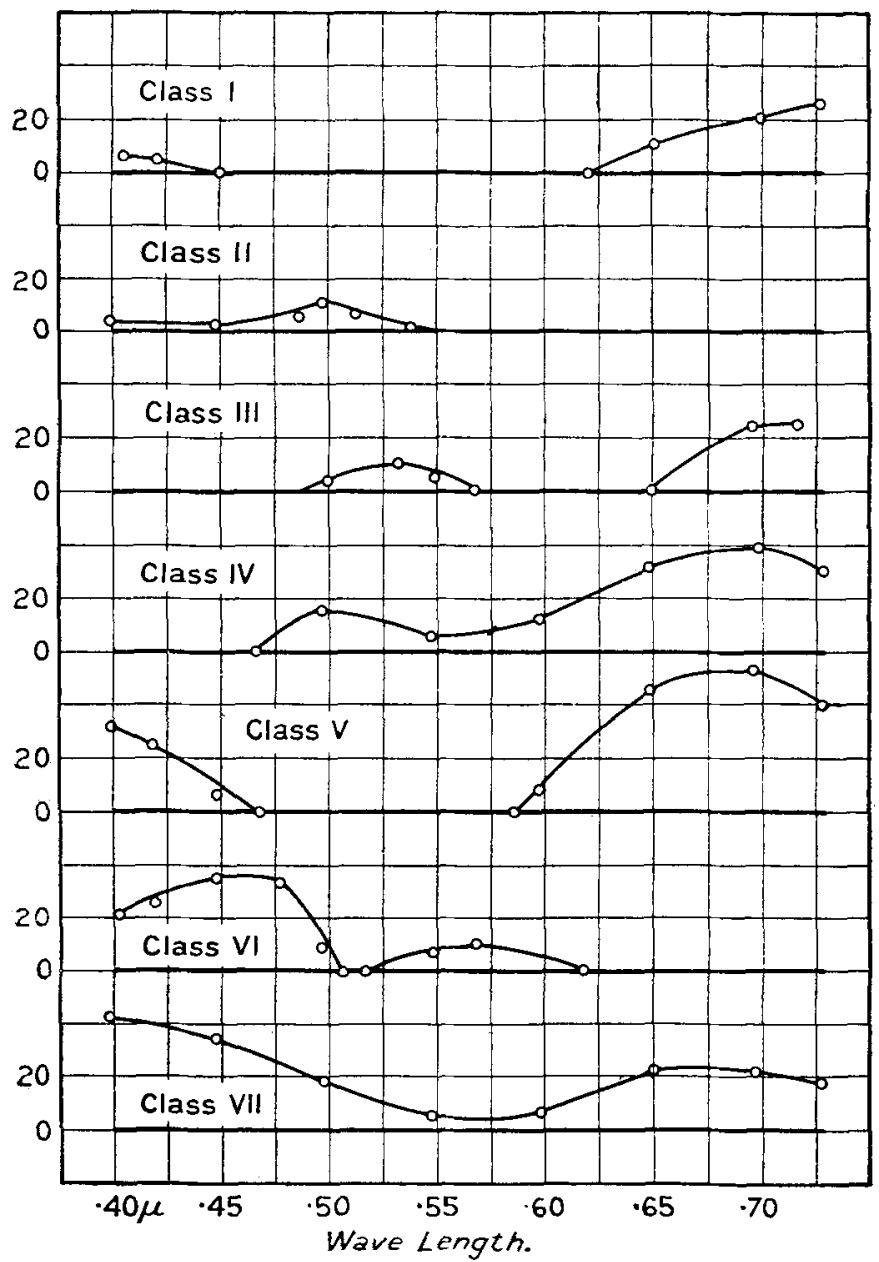

According to this theory seven general classes of colourblindness are possible: three classes when any one coloursensation is absent or defective : three classes when any two sensations are absent or defective; and one class when all three sensations are absent or defective. The seven types of 
curves in fig. 22 show all these classes excepting only that for violet. colour-blindness, for which type I have not yet found a subject.

For the purpose of comparison, I have brought together the exact hues of the primary colours according to several investigators whose experiments were conducted on the basis of the trichromatic theory. With these are included the colours selected by Hering for his theory of colour-vision, and those determined for the same thenry by the accurate experiments of Baird *.

\section{Red.}

Helmont\% ... Carmine-red; not in spectrum.

KönıG ......... Purple-red; just outside spectrum.

EXNER ......... Red complementary to $-494 \mu$. (About - $66 \mu$.)

Allex Between end of spectrum and $66 \mu$.

Red.

Hering

BAIRD

Purple-red ; non-spectral.

Purple-red; nun-spectral.
Green.

$\cdot 56 \mu$ to $\cdot 54 \mu$.

$\cdot 505 \mu$.

$.508 \mu$.

$.570 \mu$ to $\cdot 470 \mu$

Green.

$-495 \mu$.

$\cdot 490 \mu$.

There is no conflict necessarily arising between my own fundamental hues for red and green and those of Helmboltz, König, and Exner ; there is divergence in the case of violet. But if it is at all justifiable for Helmholtz and the others to differ in their green hues by nearly $\cdot 06 \mu$, no exception need be taken to my violet determination because it differs from the others by an equal amount.

In endeavouring to connect the transition points with other colour-phenomena, I have found specially suggestive the colour-sensation curves obtained by Abney and Watson, fig. 23, and by König and Dieterici, fig. 24. On each of these figures I have indicated the transition points by short vertical lines with wave-lengths attached.

In the curves of Abney and Watson the transition points $\lambda \cdot 660 \mu$ and $\lambda \cdot 470 \mu$ are practically at the ends of the sensation curve for green ; and the remaining transition points at $\lambda \cdot 420 \mu$ and $\lambda \cdot 570 \mu$ are near the ends of the sensation curve for blue. While the green and red sensation curves extend to the wave-length $\lambda \cdot 43 \mu$, yet their influence compared witlı blue seems quite negligible on the more refrangible side of $\lambda \cdot 470 \mu$. The transition point at $\lambda \cdot 570 \mu$ is also very cluse

* J. W. Baird, "The Colour Sensitivity of the Peripheral Retina," Carnegie Institution, 1905. 
to the intersection of the green and red sensation curves. The transition point at $\lambda \cdot 420 \mu$ is shown by the curves to be practically outside the influence of the red and green sensations, and hence may be regarded as a region of a single

Fig. 23.

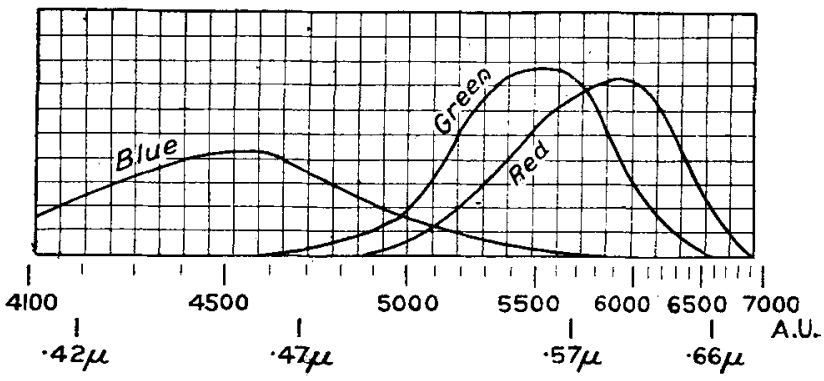

Normal Sensation Curves. (Abney and Watson.)

(From Parsous's 'Colour Vision,' p. 244.)

Fig. 24.

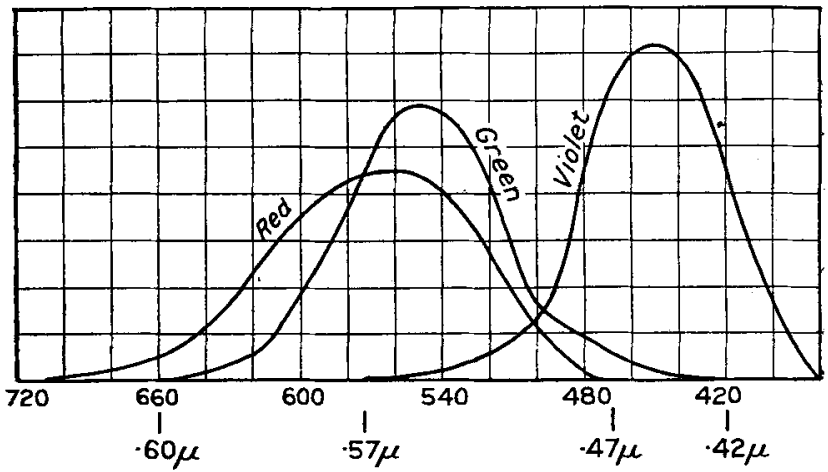

Sensation Curves. (König and Dieterici.)

(From Parsons's 'Colour Vision,' p. 222.)

pure-colour sensation. Similarly, the spectral region from the transition point $\lambda \cdot 660 \mu$ to the end of the spectrum is pure red free from the influence of the other two sensations.

'The sensation curves of König and Dieterici, fig. 24, show some differences. The ends of the green sensation curve are the transition points $\lambda \cdot 660 \mu$ and $\lambda \cdot 420 \mu$, while the transition point $\lambda \cdot 470 \mu$ is still the more refrangible end of the sensation curve for red. The transition point $\lambda \cdot 570 \mu$. 
marks one end of the sensitive curve for violet. It will be noticed that the regions between the transition points $\lambda \cdot 660 \mu$ and $\lambda \cdot 420 \mu$ and the respective ends of the spectrum are, as before, characterized by purity and simplicity of coloursensation. The transition point at $\lambda \cdot 570 \mu$ is again at the intersection of the red and green sensation curves, that is, where the two sensations balance the influence of each other, without sufficient of the third sensation to make itself perceptible. In both figures one can see reasons why the regions between $\lambda \cdot 420 \mu$ and $\lambda \cdot 470 \mu$, and between $\lambda \cdot 570 \mu$ and $\lambda \cdot 660 \mu$; should be characterized by compound sensations. But it is difficult to understand why the exceedingly complex region between $\lambda \cdot 470 \mu$ and $\lambda \cdot 570 \mu$ should exhibit, as it does, persistency curves with only one elevation in the green.

The occurrence of the four transition points at the boundaries of the sensation curves cannot be in any sense accidental, and is certainly not intentional, since the transition points were discovered long before any examination of the sensation curves was made in this connexion.

The cumulative effect of all the experimental evidence presented in this paper seems to warrant most strongly the conclusions already expressed, that there are but three colour sensations, which correspond to red, green, and violet, and that these sensations are primarily excited by hues which lie between the limits set by the four transition points.

V. The Persistence of Vision of Colours of Varying Intensity. By Frank Allen, Ph.D., F.R.S.C., Professor of Physics, University of Manitoba, Canada*.

T $\mathrm{N}$ a former communication to the Philosophical Magazine $\dagger$ a method of measuring the luminosity of the spectrum was discussed, which may also be used for the determination of the persistence of vision of colours of varying intensity. The arrangement of apparatus employed in the present investigation is very similar to that described in the paper referred to, and is shown diagrammatically in fig. 1 .

Light from the acetylene flame (A), after concentration by a lens (B), passed through an open sector $\left(90^{\circ}\right)$ of the disk (C) which was rotated by an electric motor, then through two Nicol prisms (D and E) arranged with their principal

* Communicated by the Author.

† "A New Method of Measuring the Luminosity of the Spectrum," May 1911.

Phil. Mag. S. 6. Vol. 38. No. 223. July 1919. 